\title{
ЧАСТОТНОСТЬ МАРКЕРОВ НЕВЕРБАЛЬНОЙ КОММУНИКАЦИИ В ЖЕНСКОМ ПУБЛИЦИСТИЧЕСКОМ ДИСКУРСЕ (НА МАТЕРИАЛЕ СТАТЕЙ ЭЛЛЕН БАРРИ B ГAЗETE «THE NEW YORK TIMES»)
}

\author{
Н. А. Трофимова
}

Белгородский государственный национальный исследовательский университет

\section{FREQUENCY OF NON-VERBAL COMMUNICATION MARKERS IN WOMEN'S PUBLICISTIC DISCOURSE (BASED ON THE ARTICLES OF ELLEN BARRY IN “THE NEW YORK TIMES”)}

\author{
N. A. Trofimova \\ Belgorod State National Research University
}

\begin{abstract}
Аннотация: в статье отображены результаты исследования маркеров невербальной коммуникаџии в публицистическом дискурсе Эллен Барри, журналистки «The New York Times». Несмотря на повышенное внимание специалистов, анализ научных трудов указал на проблемы определения понятий публицистического дискурса, гендера и невербальной коммуникации. При этом указано, что публицистический дискурс является одним из наиболее важных видов дискурса для изучения, что обусловлено направленностью на постоянную передачу информации о мировых событиях и жизни современных людей. В свою очередь, предполагается, что гендерные характеристики журналистов влияют на выбор средств описания различных фактов в публицистическом дискурсе. Признана значимость и актуальность изучения невербальной формы коммуникации, которая способствует раскрытию более глубокого смыслового пласта. Ввиду актуальности изучения указанных феноменов более сложная задача заключается в определении проявления гендерной составляющей в вербализованных маркерах невербальной коммуникации в публицистическом дискурсе. С этой целью использовался методологический инструментарий когнитивно-герменевтического анализа. В результате задействования данного метода проанализировано использование хронем, проксем, сенсем, кинем и такем как маркеров невербальной коммуникации на материале статей журналистки. Квантитативный метод способствовал определению частотности рассматриваемых номинантов. В статье представлен вывод о том, что наиболее частотные маркеры невербальной коммуникации в статьях журналистки Эллен Барри - это проксемы и хронемы. Со средней частотой в публицистическом дискурсе журналистки употребляются кинемы и сенсемы. Такемы определены как низкочастотные маркеры невербальной коммуникации в статьях Эллен Барри.

Ключевые слова: публицистический дискурс, гендер, невербальная коммуникация, The New York Times, Ellen Barry, когнитивно-герменевтический метод, проксема, хронема, сенсема, кинема, такема.
\end{abstract}

\begin{abstract}
: the article presents the results of a study of markers of non-verbal communication in the publicistic discourse of Ellen Barry, a journalist of "The New York Times". Despite the increased attention of specialists, the analysis of scientific works indicated the problems of defining the concepts of publicistic discourse, gender and non-verbal communication. At the same time, it is indicated that publicistic discourse is one of the most important types of discourse for study, which is due to the focus on the constant transfer of information about world events and the life of modern people. In turn, it is assumed that the gender characteristics of journalists influence the choice of means of describing various facts in publicistic discourse. The importance and relevance
\end{abstract}

(C) Трофимова Н. А., 2021

Контент доступен под лицензией Creative Commons Attribution 4.0 License.

The content is available under Creative Commons Attribution 4.0 License. 
of studying the non-verbal form of communication that contributes to the disclosure of a deeper semantic layer was recognized. In view of the relevance of studying these phenomena, a more difficult task is to determine the manifestation of the gender component in verbalized markers of non-verbal communication in publicistic discourse. For this purpose, the methodological tools of the cognitive-hermeneutic analysis were used. As a result of using this method, we analyzed the use of chronemes, proxemes, sensemes, kinemes and takemes as markers of nonverbal communication based on the journalist's articles. The quantitative method helped to determine the frequency of the considered nominees. The article concludes that the most frequent markers of non-verbal communication found in the articles of journalist Ellen Barry are proxemes and chronomes. Kinemes and sensemes are used with an average frequency in the publicistic discourse. Takemes are defined as low-frequency markers of non-verbal communication in articles by Ellen Barry.

Key words: publicistic discourse, gender, non-verbal communication, The New York Times, Ellen Barry, cognitivehermeneutic method, proxeme, chroneme, senseme, kineme, takeme.

\section{Введение}

В настоящее время исследование дискурса способствует формулировке выводов о свойствах транслируемой языковой картины мира [1, с. 47]. В свою очередь, передаваемая картина мира в публицистическом дискурсе зависит от многих факторов, включая гендер. В соответствии с данными, представленными А. Л. Кучиной, в современном дискурсе СМИ феномен гендера отличается особой актуальностью [2, с. 152]. Добавим, что разработка проблемы гендера за последние десятки лет привела к разграничению понятий «пол» и «гендер», а впоследствии - к тщательному обозрению анатомо-физиологических особенностей в системе экономических, политических и социальных координат. С заметной частотой гендер интерпретируется как фактор влияния [3, c. 296].

Тем не менее в современной науке возникает много противоречивых трактовок данного понятия. Неоднозначность характерна и для трактовки понятия самого публицистического дискурса, а также такой перспективной для исследования формы коммуникации, как «невербальная коммуникация» [4, с. 125]. При этом невербальная коммуникация зависит от тех социально-культурных ожиданий, которые адекватны в определенной коммуникативной ситуации, и своими средствами реализации соответствует им. Важность изучения указанной формы коммуникации связана с тем, что «изучение особенностей невербального поведения позволяет понять механизмы коммуникации более глубоко» [5, с. 327].

Вербальная и невербальная формы коммуникации в комплексе создают возможность основательного охвата исследуемого материала [6, с. 12], в частности моделирования публицистического дискурса с учетом гендерной составляющей языковой личности.

\section{Материалы и методы}

В качестве материала исследования нами избрана популярная американская газета «The New York Times». Стоит отметить, что «The New York Times» является примером элитарной журналистики. Такой вывод был сформулирован после тщательного обзора статей журналистов, которые в большинстве случаев писали о местных политических и общественных деятелях.

Популярная газета критикуется и за освещение определенных политических деятелей в необходимом свете. Так, как указывают исследователи, если журналисты «New York Post» описывали Дональда Трампа как будущего президента в целом положительно, то журналисты «The New York Times» при его описании использовали лексику на обозначение агрессивного поведения - "pushes, offers himself, bizarre speech, insulting etc" [7, p. 33]. Это связано с тем, что редакция газеты «The New York Times» поддерживает сторонников либерального политического подхода.

Ввиду известности и популярности данной газеты, мы полагаем, что выявление гендерных особенностей отражения различных мировых событий является важной задачей.

Когнитивно-герменевтический анализ как метод обработки статей журналистки Эллен Барри был избран с целью выявления, а также интерпретации маркеров невербальной коммуникации. В сочетании с квантитативным методом это позволило определить количественные (частотность употребляемых маркеров) и качественные (функционально-семантический аспект маркеров) характеристики маркеров невербальной коммуникации в статьях журналистки, размещенных в газете «The New York Times».

\section{Результаты исследования}

Согласно Ю. Ю. Наливайко, информация, представленная в публицистическом тексте, - это часть жизни современного человека [8, с. 46]. Соответственно, создание публицистического текста как материального аналога фиксации воспринятой информации с окружающего мира тесно связано как с вербальными, так и невербальными особенностями общения представителей с различной гендерной идентификацией.

Стоит упомянуть о том, что возникновение невербальной формы коммуникации детерминировано 
ростом потребности в коммуникации, усложнением и увеличением средств неречевой знаковой системы до того предела, когда речь смогла облегчить жизнедеятельность людей. Хотя со временем ввиду развития культурных представлений многие знаки претерпели качественные изменения, они до сих пор являются важным исследовательским материалом [9, c. 76]. Разнообразие невербальной коммуникации проявляется в сложности интерпретации мимических выражений, жестовых движений, взгляда, интонационного рисунка, стиля прически и макияжа, украшения тела элементами одежды и аксессуарами, позы, использования времени и пространства для конструкции смысловых узлов [10, с. 155]. Однако ценность невербальной коммуникации заключается в способности зафиксировать минимальные изменения в манере поведения или коммуникативной стратегии человека, тем самым углубляясь в анализе с целью постижения истинного положения вещей в разных культурных сообществах [9, с. 79].

Е. Т. Кененбаев считает, что распознание и понимание невербального поведения «способствуют достижению наивысшей степени взаимопонимания» $[11$, c. 61]. При этом исследователь представил типологию невербальной коммуникации, различая:

1) поведение, обусловленное знаками - физиологическими реакциями (дрожь, покраснение и т. п.);

2) ненамеренно проявляемые знаки - это привычки человека (например, качание ноги и т. п.);

3) собственно коммуникативные знаки - знаки, передающие определенный пласт информации о различных явлениях и событиях.

Многоплановость невербальной коммуникации предопределяет ее полифункциональность. Обобщив существующие классификации функций невербальной коммуникации, Е. Г. Задворная и А. Хонарджу выделили основные из них, среди которых - «семантическая (информационная), эмоционально-оценочная (или эмоционально-экспрессивная), регулятивная, дейктическая, выделительная, статусно-ролевая и фатическая (включающая метакоммуникативную)» [12, с. 47]. Проявление полифункциональности невербальной коммуникации характерно и для публицистического дискурса, который часто ассоциируется с манипуляцией. Так, В. А. Болдырева соотносит публицистический политический дискурс с понятием «манипуляторное прогнозирование» и отмечает их взаимосвязь в следующих категориях:

- общность мотивационно-целевого пространства - формирование и распространение влияния;

- общность базовых характеристик - эмотивность и экспрессивность изложения, использование доступного для большинства населения регистра речи и т. п.;

- общность создания особой атмосферы для иллокутивной цели, направленной на достижение пер- локутивного эффекта различными вербальными средствами [13, с. 23].

Из этого следует, что архитектоника публицистического дискурса потенциально определяет мировоззрение читателя, воспринимающего информативный массив избранного источника СМИ и разделяющего ценностные ориентиры журналистов.

Объединяя междисциплинарные данные в рамках нашего исследования публицистического дискурса журналистки «The New York Times» Эллен Барри, мы смогли выявить различные маркеры невербальной коммуникации: хронемы, проксемы, такемы, кинемы и сенсемы.

Нами было проанализировано 14 статей журналистки Эллен Барри, которые описывают различные современные проблемы экономико-политического и социально-культурологического характера в мировом масштабе. Поскольку Эллен Барри ранее была руководителем московского и Южно-азиатского бюро, занимала должность главного международного корреспондента и сейчас руководит бюро газеты в Новой Англии, мы считаем, что это влияет на тематическое разнообразие статей. Так, среди рассматриваемых статей журналистки в 4 из них описываются события в России:

1) "Duma clears way for longer terms in Russia";

2) "A Writer Invites Russia to Engage Its Painful Past";

3) "A Dress Code For Russians? Priest Chides Skimpiness";

4) "Russia Seems To Soften Its Support For Syria".

B 2 проанализированных статьях описываются события в Бангладеш:

1) "Bangladesh Orders Death for Islamist in Killings";

2) "Matriarchs' Duel for Power Threatens to Tilt Bangladesh Off Balance".

В 2 рассмотренных статьях описываются события в Индии:

1) "India Retracts Proposal on Encryption for Social Media Data After Outcry";

2) “India's 'Phone Romeos' Look for Ms. Right via Wrong Numbers".

Кроме того, по одной статье - события в следующих странах:

1) США - "U.S. trying to take monkey off the menu";

2) Великобритания - "Small Bottle' of Novichok Found by Police in U.K. Victim's Home";

3) Швеция - "In Sweden's Preschools, Boys Learn to Dance and Girls Learn to Yell”;

4) Непал - "Nepal's Young Men, Lost to Migration, Then a Quake";

5) Украина - “Thousands Join Anti-Government Rally in Ukraine".

В одной из статей рассматриваются события двух стран: 
США и Бангладеш - “To U.S. in '70s, a Dissenting Diplomat. To Bangladesh, 'a True Friend'.

Перейдем непосредственно к результатам когнитивно-герменевтического и квантитативного анализа маркеров невербальной коммуникации в публицистическом дискурсе Эллен Барри.

Наиболее частотной группой маркеров невербальной коммуникации в публицистическом дискурсе Эллен Барри являются проксемы. Говоря о проксемах в дискурсе журналистки Эллен Барри, важно обратиться к определению проксемики, которая представляет собой «совокупность проксем, т. е. способов использования пространства в процессе коммуникации» [14, с. 117].

Рассмотрим пример употребления проксемы в статье 'Small Bottle' of Novichok Found by Police in U.K. Victim's Home".

Пример 1.1. "The bottle was found in the home of Charlie Rowley, 45, in Amesbury, England".

«В Великобритании небольшая бутылка была обнаружена в доме 45-летнего жителя Чарли Роули, жсителя Эймсбери» (здесь и далее перевод наш. H. T.).

Как видим, в вышеприведенном предложении используются проксемы-топонимы, выраженные собственными существительными, указывают на местонахождение потерпевшего, Чарли Роули, от нервно-паралитического вещества «Новичок». Стоит учитывать, что проксема “England”, является гиперонимом относительно проксемы “Amesbury” (графство Уолшир).

Статья "U.S. trying to take monkey off the menu" характеризуется наличием нескольких маркеров, указывающих на пространственные параметры осуществления борьбы с торговлей мяса диких животных в США. Рассмотрим один из них на примере прямой речи Эдвард Лама Уонкерера, преподавателя Университета Темпл (штат Пенсильвания) в статье журналистки.

Пример 1.2. "Until firly recently, bushmeat was sold openly in immigrant neighborhoods, said Wonkeryor, adding that the case against Manneh had made it more expensive and hard to find".

«"До недавнего времени в иммигрантских кварталах мясо диких животных продавалось в открытую”, - заявил Вонкерер, добавив, что дело против Манне повысило стоимость и усложнило доступность мяса».

Проксема "in immigrant neighborhoods" содержит как пространственный, так и этнокультурный элементы смысла. Это связано с ассоциативным рядом, возникающим вследствие ознакомления с бедной и сложной жизнью и бытом иммигрантов.

Следующим высокочастотным маркером невербальной коммуникации в статьях журналистки явля- ется хронема. Хронема - «это языковая единица, вербализующая темпоральный маркер в повествовательном контуре текста, репрезентирующий время как компонент невербального кода коммуникации» $[15$, c. 141$]$.

В результате проведения структурного анализа хронем мы выяснили, что доминирующим типом среди хронем в статьях журналистки значатся одноядерные хронемы.

Рассмотрим примеры хронем в статьях Эллен Барри.

Одна из статей, “India's 'Phone Romeos' Look for Ms. Right via Wrong Numbers", информирует читателей о том, что полиция в Индии выслеживает так называемых «телефонных Ромео» (“Phone Romeos"), набирающих случайные номера мобильных телефонов с целью поиска девушки для романтических отношений.

Пример 2.1. "Summoned to the police station, $\mathrm{Mr}$. Tiwari confessed readily and with clasped hands he beseeched the police not to imprison him. His phone calls, he explained in an interview, should better be understood as part of his search for a soul mateu "...». The police were not impressed, and held him in custody for 15 days".

«Вызванный в полицейский участок, г-н Тивари полностью признал свою вину и, скрестив руки, молил о том, чтобы полицейские не сажали его в тюрьму. Согласно данным интервью, телефонные звонки г-на Тивари стоит расценивать скорее как одну из попьток поиска родственной души “...” На полицию его речь не прочзвела впечатления, и он находился под стражей в течение 15 дней».

Как видим, в проанализированном фрагменте используется одноядерная хронема "for 15 days". Ядром хронемы является темпоральная лексема, представленная нарицательным существительным во множественном числе “days". Использованная хронема в представленном контексте конкретизирует временные рамки нахождения г-на Тивари под стражей, а также указывает на их пролонгированный характер. Соответственно, Эллен Барри акцентирует внимание на продолжительности наказания индийского мужчины за телефонный звонок случайной девушке.

В другой статье, “A Dress Code For Russians? Priest Chides Skimpiness”, журналистка отображает позицию представителей Русской православной церкви, в частности протоиерея Всеволода Чаплина, относительно выбора россиянками слишком откровенной одежды в ущерб их скромности.

Рассмотрим отрывок статьи с хронемой.

Пример 2.2. "He argued that clothing was not a private business, and that he hoped that Russia would soon be a place where scantily dressed women or men in track suits would not be admitted into public venues". 
«Он утверждал, что одежда не является личным делом каждого, и выразил надежду, что вскоре Россия станет страной, в которой женщчинам в откровенном наряде и мужчинам в спортивном костюме будет запрещчено посещтать общчественные места».

Одноядерная хронема “soon”, выраженная наречием времени, указывает на предельность мер в отношении женского и мужского костюмов которые, по мнению протоиерея, должны претерпеть незамедлительные изменения. Журналистка отображает нетерпимость протоиерея к отсутствию чувства меры и скромности современных россиянок, а также нетерпеливость, направленную на скорейшее обновление публичного дресс-кода в стране.

В публицистическом дискурсе Эллен Барри с достаточной частотой употребляются и сенсемы. При этом «сенсорика как сегмент невербального кода общения объединяет совокупность информации органов чувств - сенсем» [14, с. 118].

Проанализируем использование сенсемы на примере отрывка статьи “А Writer Invites Russia to Engage Its Painful Past”, посвященного роману Елены Чижовой, Лауреата «Русского Букера - 2009», под названием «Время женщин».

Пример 3.1. " And 40 years later, the insistent voices of old women began to declaim in Ms. Chizhova's head, and she sat down to write a novel".

«И спустя 40 лет в ушах госпожи Чижовой настойчиво звучали голоса пожильх женщцин, $u$ она села за написание романа».

Сенсемы "the insistent voices" и "declaim", в первом случае выраженные артиклем, прилагательным в сочетании с именем существительным, а во второминфинитивом, передают информацию не только о факте, но и интенсивности звучания голосов, которые вспоминала писательница перед работой над литературным трудом.

В архитектонике публицистического дискурса Эллен Барри зафиксировано также достаточно частое использование кинем как единиц, вербализирующих «проявления двигательной активности человека, которые в лингвистике получили название «кинесических движений, или кинесики» [16, с. 256].

Нами выявлен отрывок статьи "Nepal's Young Men, Lost to Migration, Then a Quake" с концентрацией нескольких кинем, позволяющих воссоздать картину погребального костра в районе Гонгабу (Непал). Ввиду серьезных экономических проблем многие мужчины покидали родную страну для работы за границей, несмотря на риск смерти. В то же время землетрясение в Непале разрушило многие дома, и оставшимся женщинам, детям и пожилым людям приходилось хоронить погибших родственников.
Рассмотрим выбранный отрывок статьи.

Пример 4.1. “Three men hoisted Mr. Chapagain's body on a plastic sheet and deposited it on the pyre. One took a handful of water from the Ganges River and dripped it into the mouth, and then drizzled his body with clarified butter to speed the burning. Then they stacked the body with logs until only one hand could be seen dangling down, its fingers curled".

"Трое мужчин уложили тело г-на Чапагейна на полиэтиленовую пленку и бросили его на костер. Один из мужчин зачерпнул горсть воды из реки Ганг и закапал ее в рот, затем он побрызгал на тело г-на Чапагейна топленое масло, чтобы ускорить произесс горения. Затем они обкладывали тело бревнами, пока не осталась видна свисающая вниз рука со скрюченными пальцами.

Исходя из примера 4.1, нам удалось зафиксировать преобладание кинем как маркеров невербальной коммуникации, описывающих последовательность действий в сцене сжигания тела погибшего мигранта.

Среди маркеров невербального кода наименее употребительными в статьях Эллен Барри являются такемы. Такемы передают специфику «невербального общения людей с помощью прикосновений» $[17$, c. 213].

В статье "In Sweden's Preschools, Boys Learn to Dance and Girls Learn to Yell” мы выявили такему, указывающую на типичное поведение детей. Обычно дети, желая завладеть игрушкой, наносят вред другим детям посредством физического контакта.

Рассмотрим данный фрагмент текста.

Пример 5.1. "If another child took her toys, she would whimper".

«Если другой ребенок забирал ее игрушки, она хлюпала».

В представленном предложении имплицитная такема “child took her toys” подразумевает тактильный контакт, когда один из детей пытается выхватить игрушки у другого ребенка и при этом может хватать его за руки, толкать, дергать и т. д.

\section{Заключение}

Мы пришли к выводу об актуальности изучения как гендерной проблематики, так и невербальной коммуникации в рамках разрабатываемой теории публицистического дискурса. Несмотря на пристальное внимание к данной проблеме, понятия «невербальная коммуникация», «гендер» и «публицистический дискурс» не получили еще своего окончательного оформления в научной парадигме.

С целью исследования дискурса Эллен Барри, журналистки газеты «The New York Times», мы задействовали методологический аппарат когнитивно-герменетивного и квантитативного анализа. Основываясь на данных исследования маркеров невер- 
бального кода коммуникации в публицистическом дискурсе Эллен Барри, мы обнаружили, что в статьях журналистки «The New York Times» высокочастотными маркерами невербальной коммуникации являются проксемы и хронемы. Сенсемы и кинемы употребляются со средней частотой, тогда как такемы значатся как низкочастотные маркеры.

\section{ЛИТЕРАТУРА}

1. Тарасова М. С. Роль языковой личности в дискурсе // Вестник Московского государственного областного университета. Серия: Русская филология. 2019. № 1. С. 41-50.

2. Кучина А. Л. Коммуникативная личность телеведущих информационно-аналитических шоу : гендерный аспект // Медиасреда. 2020. № 1. С. 149-154.

3. Реснянский С. И., Амиантова И. С. Гендер в российской истории : обзор новейших исследований // Вестник РУДН. Серия: История России. 2019. № 2, вып. 18. С. 278-301.

4. Кудинова Е. С. Современные методы исследования речежестового взаимодействия // Вестник Моск. гос. лингв. ун-та. Гуманитарные науки. 2020. № 1 (830). C. $122-133$.

5. Даниленко И. А. Репрезентанты невербального кода коммуникации в номинативном поле концепта // Международный журнал экспериментального образования. 2016. № 4-2. С. 327-330.

6. Айсувакова Т. П., Дмитриев М. М. Теоретические основы взаимосвязи вербальных и невербальных средств общения в межличностной коммуникации // Педагогический вестник. 2019. Вып. 8. С. 12-14.

7. Trajkova Z. Manipulating truth in media discourse // Journal of Contemporary Philology. 2019. № 2 (1). Pp. 24- 46.

8. Наливайко Ю. Ю. Журналистский текст публицистического дискурса : поиск универсальной модели построения // Вестник Донецкого национального университета. Серия Д: Филология и психология. 2019. № 1. C. $46-49$.

9. Берестенников А. О., Буряк Н. Ю. Невербальное общение как средство кросс-культурной коммуникации // Тенденции развития науки и образования. 2020. № 585. С. 76-79.

10. Украинский E. С. Проблема невербального поведения в психологии // Вестник молодого ученого Кузбасского института. Кузбасс, 2019. С. 154-155.

11. Кененбаев E. T. Невербальная коммуникация в социальной жизни // International scientific review. 2019. № LXVII. C. 60-62.

12. Задворная Е. Г., Хонарджу А. Функции невербальных компонентов коммуникации окулесического типа в мужском и женском коммуникативном поведении. // Материалы ежегод. науч. конф. преподавателей и аспирантов ун-та, 18-19 апреля 2019 г. : в 5 ч. Минск : МГЛУ, 2019. Ч. 3. С. 46-47.

13. Болдырева В. А. Функциональная прагматика интенциональных манипулятивных маркеров публици- стического политического дискурса // Актуальные проблемы филологии и педагогической лингвистики. 2019. № 4. С. 20-26.

14. Огнева E. А. Вербальные маркеры невербального кода в тексте оригинала и перевода // Альманах современной науки и образования. Тамбов, 2010. № 2-2. C. $116-118$.

15. Огнева $E$. $A$. Темпоральная архитектоника концептосферы художественного текста // Приоритетные направления лингвистических исследований : общетеоретические, когнитивные, коммуникативно-прагматические и функционально-грамматические аспекты языка : коллективная научная монография / [под ред. А. Г. Бердниковой]. Новосибирск : СибАК, 2013. C. $138-155$.

16. Хлыстова В. Г. Кинема как основная единица кинесики (на материале английского и русского языков) // Актуальные проблемы филологии и педагогической лингвистики. 2008. № 10. С. 256-259.

17. Сысоева А. В., Чернявская Я. В. Особенности невербального общения и его роль в процессе коммуникации // Инновационные подходы в решении проблем современного общества : сб. ст. Междунар. науч.-практ. конф. Пенза, 2018. С. 211-213.

\section{ИСТОЧНИКИ}

1. Barry Ellen. Duma clears way for longer terms in Russia. URL: https://www.nytimes.com/2008/11/14/world/ europe/14iht-15duma.17840632.html

2. Barry Ellen. A Writer Invites Russia to Engage Its Painful Past. URL: https://www.nytimes.com/2010/03/06/ world/europe/06author.html

3. Barry Ellen. A Dress Code For Russians? Priest Chides Skimpiness. URL: https://www.nytimes.com/2011/ 01/19/world/europe/19russia.html

4. Barry Ellen. Russia Seems To Soften Its Support For Syria. URL: https://www.nytimes.com/2012/03/21/world/ europe/russia-appears-to-soften-adamant-position-in-syria-conflict.html

5. Barry Ellen. Bangladesh Orders Death for Islamist in Killings. URL: https://www.nytimes.com/2013/09/18/ world/asia/islamist-in-bangladesh-sentenced-to-death-inkillings.html

6. Barry Ellen. Matriarchs' Duel for Power Threatens to Tilt Bangladesh Off Balance. URL: https:/www.nytimes. com/2014/01/12/world/asia/matriarchs-duel-for-powerthreatens-to-tilt-bangladesh-off-balance.html

7. Barry Ellen. India Retracts Proposal on Encryption for Social Media Data After Outcry. URL: https:/www. nytimes.com/2015/09/23/world/asia/india-withdraws-social-media-data-proposal-after-outcry.html

8. Barry Ellen. India's 'Phone Romeos' Look for Ms. Right via Wrong Numbers. URL: https://www.nytimes. com/2017/03/22/world/asia/indias-phone-romeos-look-forthe-right-one-through-wrong-numbers.html

9. Barry Ellen. U.S. trying to take monkey off the menu. URL: https://www.nytimes.com/2007/11/18/world/americas/18iht-monkey.1.8374575.html 
10. Barry Ellen. 'Small Bottle' of Novichok Found by Police in U.K. Victim's Home. URL: https://www.nytimes. com/2018/07/13/world/europe/uk-novichok-amesbury.html

11. Barry Ellen. In Sweden's Preschools, Boys Learn to Dance and Girls Learn to Yell. URL: https://www.nytimes. com/2018/03/24/world/europe/sweden-gender-neutralpreschools.html

12. Barry Ellen. Nepal's Young Men, Lost to Migration, Then a Quake. URL: https://www.nytimes.com/2015/05/05/ world/asia/nepal-already-stripped-of-young-men-faces-adarker-problem.html

13. Barry Ellen. Thousands Join Anti-Government Rally in Ukraine. URL: https://www.nytimes.com/2009/04/04/ world/europe/04ukraine.html

14. Barry Ellen. To U.S. in '70s, a Dissenting Diplomat. To Bangladesh, 'a True Friend' URL: https://www.nytimes. com/2016/06/28/world/asia/bangladesh-archer-blood-cable. html

\section{REFERENCES}

1. Tarasova M. S. Rol' yazykovoj lichnosti v diskurse [The role of a linguistic personality in discourse]. In: Vestnik Moskovskogo gosudarstvennogo oblastnogo universiteta. Seriya: Russkaya filologiya. 2019. No. 1. Pp. 41-50.

2. Kuchina A. L. Kommunikativnaya lichnost' televedushchih informacionno-analiticheskih shou: gendernyj aspekt [Communicative personality of TV presenters of information and analytical shows: gender aspect]. In: $\mathrm{Me}$ diasreda. 2020. No. 1. Pp. 149-154.

3. Resnyanskij S. I., Amiantova I. S. Gender v rossijskoj istorii: obzor novejshih issledovanij [Gender in Russian history: an overview of the latest research]. In: Vestnik RUDN. Seriya: Istoriya Rossii. 2019. No. 2, vyp. 18. Pp. 278-301.

4. Kudinova E. S. Sovremennye metody issledovaniya rechezhestovogo vzaimodejstviya [Modern research methods of speech interaction]. In: Vestnik Moskovskogo gosudarstvennogo lingvisticheskogo universiteta. Gumanitarnye nauki. 2020. No. 1 (830). Pp. 122-133.

5. Danilenko I. A. Reprezentanty neverbal'nogo koda kommunikacii v nominativnom pole koncepta [Representatives of the non-verbal communication code in the nominative field of the concept]. In: Mezhdunarodnyj zhurnal eksperimental'nogo obrazovaniya. 2016. No. 4-2. Pp. 327 330 .

6. Ajsuvakova T. P., Dmitriev M. M. Teoreticheskie osnovy vzaimosvyazi verbal'nyh i neverbal'nyh sredstv obshcheniya v mezhlichnostnoj kommunikacii [Theoretical foundations of the relationship between verbal and non-verbal means of communication in interpersonal communication]. In: Pedagogicheskij vestnik. 2019. Vyp. 8. Pp. 12-14.

7. Trajkova Z. Manipulating truth in media discourse [Manipulating truth in media discourse]. In: Journal of Contemporary Philology. 2019. № 2 (1). Pp. 24-46.

8. Nalivajko Yu. Yu. Zhurnalistskij tekst publicisticheskogo diskursa: poisk universal'noj modeli postroeniya [Journalistic text of publicistic discourse: search for a uni- versal model of construction], In: Vestnik Doneckogo nacional'nogo universiteta. Seriya D: Filologiya i psihologiya. 2019. No. 1. Pp. 46-49.

9. Berestennikov A. O., Buryak N. Yu. Neverbal'noe obshchenie kak sredstvo kross- kul'turnoj kommunikacii [Non-verbal communication as a means of cross-cultural communication]. In: Tendencii razvitiya nauki i obrazovaniya. 2020. No. 58-5. Pp. 76-79.

10. Ukrainskij E. S. Problema neverbal'nogo povedeniya $\mathrm{v}$ psihologii [The problem of non-verbal behavior in psychology]. In: Vestnik molodogo uchenogo Kuzbasskogo instituta. Sbornik nauchnyh statej. 2019. Pp. 154-155.

11. Kenenbaev E. T. Neverbal'naya kommunikaciya v social'noj zhizni [Non-verbal communication in social life]. In: International scientific review. 2019. No. LXVII. Pp. 60-62.

12. Zadvornaya E. G., Honardzhu A. Funkcii neverbal'nyh komponentov kommunikacii okulesicheskogo tipa v muzhskom i zhenskom kommunikativnom povedenii [Functions of non-verbal communication components of the ocular type in male and female communicative behavior]. In: Materialy ezhegodnoj nauchnoj konferencii prepodavatelej $i$ aspirantov universiteta, 18-19 aprelya $2019 \mathrm{~g}$. : v 5 ch. Minsk: MGLU, 2019. CH. 3. Pp. 46-47.

13. Boldyreva V. A. Funkcional'naya pragmatika intencional'nyh manipulyativnyh markerov publicisticheskogo politicheskogo diskursa [Functional pragmatics of intentional manipulative markers of publicistic political discourse]. In: Aktual'nye problemy filologii i pedagogicheskoj lingvistiki. 2019. No. 4. Pp. 20-26.

14. Ogneva E. A. Verbal'nye markery neverbal'nogo koda $\mathrm{v}$ tekste originala i perevoda [Verbal markers of the non-verbal code in the text of the original and translated text]. In: Al'manah sovremennoj nauki i obrazovaniya. Tambov, 2010. No. 2-2. Pp. 116-118.

15. Ogneva E. A. Temporal'naya arhitektonika konceptosfery hudozhestvennogo teksta [Temporal architectonics of the conceptual sphere of a literary text]. In: Prioritetnye napravleniya lingvisticheskih issledovanij: obshcheteoreticheskie, kognitivnye, kommunikativno-pragmaticheskie $i$ funkcional'no-grammaticheskie aspekty yazyka: kollektivnaya nauchnaya monografiya; [pod red. A.G. Berdnikovoj]. Novosibirsk: Izd. «SibAK», 2013. Pp. 138-155.

16. Hlystova V. G. Kinema kak osnovnaya edinica kinesiki (na materiale anglijskogo i russkogo yazykov) [Kineme as the main unit of kinesics (based on the material of English and Russian languages)]. In: Aktual'nye problemy filologii i pedagogicheskoj lingvistiki. 2008. No. 10. Pp. 256-259.

17. Sysoeva A. V., Chernyavskaya Ya. V. Osobennosti neverbal'nogo obshcheniya i ego rol' v processe kommunikacii [Features of non-verbal communication and its role in the communication process]. In: Bnnovacionnye podhody $v$ reshenii problem sovremennogo obshchestva. Cbornik statej Mezhdunarodnoj nauchno-prakticheskoj konferencii. Penza, 2018. Pp. 211-213. 


\section{SOURCES}

1. Barry Ellen. Duma clears way for longer terms in Russia. Available at: https://www.nytimes.com/2008/11/14/ world/europe/14iht-15duma.17840632.html

2. Barry Ellen. A Writer Invites Russia to Engage Its Painful Past. Available at: https://www.nytimes. com/2010/03/06/world/europe/06author.html

3. Barry Ellen. A Dress Code For Russians? Priest Chides Skimpiness. Available at: https://www.nytimes. com/2011/01/19/world/europe/19russia.html

4. Barry Ellen. Russia Seems To Soften Its Support For Syria. Available at: https:/www.nytimes.com/2012/ 03/21/ world/europe/russia-appears-to-soften-adamant-position-in-syria-conflict.html

5. Barry Ellen. Bangladesh Orders Death for Islamist in Killings. Available at: https://www.nytimes.com/2013/ 09/18/world/asia/islamist-in-bangladesh-sentenced-todeath-in-killings.html

6. Barry Ellen. Matriarchs' Duel for Power Threatens to Tilt Bangladesh Off Balance. Available at: https://www. nytimes.com/2014/01/12/world/asia/matriarchs-duel-forpower-threatens-to-tilt-bangladesh-off-balance.html

7. Barry Ellen. India Retracts Proposal on Encryption for Social Media Data After Outcry. Available at: https:// www.nytimes.com/2015/09/23/world/asia/india-withdraws-social-media-data-proposal-after-outcry.html

Белгородский государственный начиональный исследовательский университет

Трофимова Н. А., ассистент кафедры иностранныхх языков, аспирант кафедры романо-германской филологии Института межкультурной коммуникации и международных отношений

E-mail:translatorn@mail.ru

Поступила в редакиию 8 февраля 2021 2.

Принята к публикачии 22 марта 2021 г.

\section{Для цитирования:}

Трофимова Н. А. Частотность маркеров невербальной коммуникации в женском публицистическом дискурсе (на материале статей Эллен Барри в газете «Тhe New York Times») // Вестник Воронежского государственного университета. Серия: Лингвистика и межкультурная коммуникация. 2021. № 2. С. 83-90. DOI: https://doi.org/10.17308/lic.2021.2/3418
8. Barry Ellen. India's 'Phone Romeos' Look for Ms. Right via Wrong Numbers. Available at: https://www.nytimes.com/2017/03/22/world/asia/indias-phone-romeoslook-for-the-right-one-through-wrong-numbers.html

9. Barry Ellen. U.S. trying to take monkey off the menu. Available at: https://www.nytimes.com/2007/11/18/world/ americas/18iht-monkey.1.8374575.html

10. Barry Ellen. 'Small Bottle' of Novichok Found by Police in U.K. Victim's Home. Available at: https://www. nytimes.com/2018/07/13/world/europe/uk-novichok-amesbury.html

11. Barry Ellen. In Sweden's Preschools, Boys Learn to Dance and Girls Learn to Yell. Available at: https://www. nytimes.com/2018/03/24/world/europe/sweden-gender-neutral-preschools.html

12. Barry Ellen. Nepal's Young Men, Lost to Migration, Then a Quake. Available at: https://www.nytimes. com/2015/05/05/world/asia/nepal-already-stripped-ofyoung-men-faces-a-darker-problem.html

13. Barry Ellen. Thousands Join Anti-Government Rally in Ukraine. Available at: https://www.nytimes. com/2009/04/04/world/europe/04ukraine.html

14. Barry Ellen. To U.S. in '70s, a Dissenting Diplomat. To Bangladesh, 'a True Friend'. Available at: https://www. nytimes.com/2016/06/28/world/asia/bangladesh-archer-blood-cable.html

\section{Belgorod State National Research University}

Trofimova N. A., Assistant of the Foreign Languages Department, Post-graduate Student of the Romance and Germanic Philology and Cross-Cultural Communication Department of the Institute of Cross-cultural Communications and International Relations

E-mail:translatorn@mail.ru

Received: 8 February 2021

Accepted: 22 March 2021

\section{For citation:}

Trofimova $N$. A. Frequency of non-verbal communication markers in women's publicistic discourse (based on the articles of Ellen Barry in "The New York Times"). Proceedings of Voronezh State University. Series: Linguistics and Intercultural Communication. 2021. No. 2. Pp. 83-90. DOI: https://doi.org/10.17308/lic.2021.2/3418 